\title{
Cómo aproximarnos a la cuestión de la democracia en Centroamérica
}

Mario Salazar Valiente

La verdad es siempre concreta.

Lenin

L Las presentes reflexiones se orientan hacia el debate de las formas democráticas en que tienden a expresarse los movimientos de la región, muy especialmente en lo que concierne al Estado revolucionario nicaragüense y su régimen. Conviene la discusión del tema de la democracia en su relación con el movimiento real latinoamericano, particularmente con los procesos que integran la revolución centroamericana.

El tema ha adquirido vigencia en los últimos tiempos. Se ha puesto de moda, por así decirlo. En diversos círculos políticos e intelectuales de los países de América Latina se impone redefinir la democracia. México mismo es escenario de tal preocupación. En ello han influido los sucesos del sur del continente y el consecuente despertar y movilización de las fuerzas democráticas. Los movimientos de transición y luchas por la "recuperación democrática" que se observan en Argentina, Chile, Brasil, Uruguay, Bolivia y otros países son determinantes del fenómeno aludido. Y también lo es el impacto que, en el espacio de actividades de los científicos sociales, viene produciendo la revolución centroamericana y su resultado inmediato: la Nicaragua sandinista.

Con signo negativo también ha contribuido al replanteamiento de la democracia el proceso contrarrevolucionario encabezado por el gobierno de Ronald Reagan. Nos estamos refiriendo al esfuerzo sostenido de la política de Estados Unidos - que no es nueva, obviamente- para manipular e imponer un estereotipo de la democracia. En Centroamérica ha sido más evidente el recurso del gobierno estadunidense a un cierto concepto estereotipado de democracia, esgrimiéndolo en contra de la revolución nicaragüense y los movimientos de cambio revolucionario en El Salvador y Guatemala.

Un sintoma del fenómeno: la terminología vinculada al tema de la estrategia de desarrollo ha cambiado en los últimos años en los foros internacionales. Ahora, donde se discuten alternativas y tácticas de desarrollo, se torna obligado el tratamiento de temas como la participación popular, la democracia, etcétera.

En los últimos tiempos, la lucha ideológica en relación a tópicos como el de la democracia ha llevado mucha agua al molino del campo consrvador. ${ }^{1}$ Una suerte de verbalismo más o menos anárquico, en el

\footnotetext{
'Hagamos referencia a título de ejemplos a algunos trabajos publicados en México. Véase: Octavio Paz, "La democracia en América Latina"; Carlos Rangel, "La inestable Latinoamérica"; Carlos Franqui, "Tiempos dictatoriales"; Enrique Krauze, "Por una democracia sin adjetivos"; Jorge Edwards, "Chile: verdades y leyendas"; José Miguel Oviedo, "Perú: la democracia sin encantos"; Rodolfo Pastor, "Una propuesta para Centroamérica"; Juan Nuño, "La democracia en Venezuela"; Marcos Palacios, "La democracia en Colombia"; Antonio Miramón y Horacio Crespo, "Argentina: vuelta a la democracia". Todos aparecen en América Latina: desventuras de la democracia, Joaquín Mortiz-Planeta, México, 1984. Entre otros autores europeos véase Norberto Bobbio, El futuro de la democracia, FCE, México, 1986.
} 
que se hallan presentes las posiciones de clase, ha logrado imponer la idea de que hablar de democracia es hacer referencia a la democracia capitalista, burguesa o formal. Dentro de una línea de pensamiento totalmente reaccionaria y maniquea, se ha excluido el término democracia de todo aquello que atañe à los países socialistas. Cuando se habla de democracia, automáticamente, a consecuencia de un tácito código neoconservador, se entiende que se trata de la democracia formal burguesa. Ipso facto, los países socialistas no pueden expresarse como democracias. Para ellos, el calificativo que se porta en el habla o en lo escrito es el de totalitarios. Se ha configurado un estereotipo de democracia identificándola, en lo sustancial, con elecciones generales de las que se llevan a efecto, con características de normalidad, en los países capitalistas desarrollados.

Se busca la identidad entre países capitalistas desarrollados y democracia, por una parte, y el nexo de los países socialistas con autoritarismo o totalitarismo, por la otra. En el campo revolucionario mundial, determinadas tendencias han coadyuvado en la dirección apuntada, especialmente dentro de la vertiente eurocomunista. Se niega hasta la posibilidad de una democracia socialista o popular de signo diferente a la democracia capitalista. En México se plantea, dentro del torrente de pensamiento conservador, el concepto "democracia sin adjetivos". Se palpa que algunas, quizás la mayoría, de las fuerzas progresistas, han caido en la trampa ideológica, haciéndole el juego al neoconservadurismo que invade a Europa, Estados Unidos y buena parte de América Latina.

Jamás se escucha una voz que, objetivamente, plantee y analice los espacios democráticos concretos que, dentro de la totalidad dialéctica social, pueden tener eficacia en cualquier país, sea Estados Unidos, México, Cuba o Nicaragua. Casi toda la discusión habida en torno a la democracia ha sido incapaz de superar el nivel de las generalidades planteadas a priori. ${ }^{2}$ El razonamiento maniqueo y anticientífico es el siguiente: en Estados Unidos hay elecciones generales para presidente, diputados, etc.; conclusión, es un país democrático. Los mecanismos de dirección y definición de los titulares de los órganos estatales de Cuba no siguen un procedimiento igual, idéntico; ello significa que es un régimen totalitario o antidemocrático, etc. En tal maniqueísmo ha

\footnotetext{
${ }^{2}$ Además de los textos antes citados véase: Alán Arias Marin, "Meditación preliminar para la discusión de la democracia en América Latina"; Carlos Pereyra, "Filosofía y democracia"; Arnaldo Córdova, "La democracia mexicana"; José María Calderón, "Capitalismo, crisis y democracia", mimeo., textos de conferencias compilados por Luis Gómez Sánchez, a publicar por el FCE. Véase también: Lucio Oliver Costilla, "La historia y la teoría en la construcción de un nuevo orden democrático en América Latina"; Raquel Sosa Elizaga, "Las dificultades de la democracia en América Latina"; Teresa Castro Escudero, "Proceso de democratización en América del Sur: el caso de Chile", ponencia ante el XVI Congreso Latinoamericano de Sociología; Pablo A. Marínez, "Democracia y soberanía nacional. Dos metas insuperables en el Caribe. El caso de República Dominicana", textos mimeografiados; Mario Lungo, "Fuerzas armadas y democratización en Centroamérica"; Edelberto Torres Rivas, "Centroamérica: guerra, transición y democracia"; César A. Barrantes A., "El discurso del Estado y la democracia en el pensamiento latinoamericano"; Manuel Rojas Bolaños, "Costa Rica: una crisis politica con sordina", ponencias ante el VII Congreso Centroamericano de Sociología, Tegucigalpa, 1986. En revistas mexicanas como Cuadernos Politicos, Nexos. Crítica, Dialéctica y muchas más, han aparecido muchos textos sobre el tema. Debe decirse que, con muy contadas excepciones, los trabajos mencionados en esta nota y en la anterior no superan las generalidades apriorísticas criticadas en este artículo.
} 
incurrido el debate abierto, al menos en México, con la tácita complacencia (y justificación) de elementos "de izquierda".

Lo absurdo y falaz del razonamiento es comprobable fácilmente. Veamos un ejemplo: la decisión adoptada legalmente, y ratificada por los órganos representativos de Estados Unidos, de invadir militarmente Granada, vulnerando su soberanía, derecho de autodeterminación y demás principios del ineficaz derecho internacional, no altera la índole democrática (en general) del gobierno estadunidense. Si el método de las generalidades apuntadas a priori, apoyadas en simples normas fundamentales de tipo procesal ("conjunto de reglas que establecen quién está autorizado para tomar las decisiones colectivas y bajo qué procedimientos", escribe N. Bobbio) no es superado en dirección hacia la concreción, no damos un paso firme hacia el conocimiento de la verdad, que es siempre concreta. En relación a Granada, Agustín Cueva apunta certeramente que la medida adoptada por el gobierno de Reagan, y ratificada, muy constitucionalmente, nos llevaría a pensar en una democracia imperial o imperialista, utilizando el adjetivo con el consiguiente disgusto de Enrique Krauze y compañia.

Pensamos que en el estudio de la problemática relativa a la democracia debe seguirse otro método. Las generalidades, que tanto abundan en la producción intelectual resultante de la polémica abierta hace algunos años en nuestros países, Estados Unidos y Europa, nada agregan al esclarecimiento del problema y conocimiento de la realidad y sí mucho a la confusión generada.

Claro es que se debe explorar, investigar, la cuestión de la representación fundamentada en elecciones generales respecto a órganos estatales ejecutivos, legislativos, judiciales, municipales, etc. Pero ello no basta. ${ }^{3}$

Es preciso indagar sobre la participación colectiva y vida interior cotidianas en todos los espacios de la sociedad civil y de la sociedad política. Esto es, introducir la investigación en las entidades sindicales, corporativas, políticas, en sus interrelaciones con el Estado; en las iglesias y el entorno de sus prácticas; en la escuela, en todas las esferas e instancias de la educación; en el ámbito de los medios de comunicación de masas y sus nexos con el estado, grupos minoritarios, poderes económicos elitistas, etc.; en el funcionamiento concreto de los medios de comunicación de masas, sus contenidos culturales, ideológicos y educativos, en relación con la soberanía nacional, la cultura nacional, el interés de las masas productoras o del lucro capitalista, etc.; en la fábrica y su vida interna, comprendiendo el problema que implica el "despotismo fabril", la "jerarquización laboral y salarial",

\footnotetext{
3 "Al hablar de la democracia es necesario incluir por lo menos cinco categorías: la represión. la negociación. la representación, la participación y la mediación", escribe Pablo González Casanova. En otra parte de su texto leemos: "En el análisis de cualquier democracia cabe ver el contexto de la represión física, moral y económica contra las personas como individuos y como colectividades, como personas y como pueblos o como clases, como violación de derechos de individuos o como violación de derechos de colectividades". Y agrega más adelante: "Es cierto que parece demagógico hablar de la democracia con hambre o de la democracia con andrajos, pero se trata de un fenómeno significativo que vale la pena enunciar para saber de qué democracia estamos hablando". El interesante trabajo de Pablo González Casanova, cuyo contenido compartimos, plantea ciertos elementos metodológicos mínimos que deben insertarse en toda investigación seria sobre la democracia, particularmente sobre la democracia en nuestros paises latinoamericanos. "Cuando hablamos de democracia, ¿de qué hablamos?", UnomásUno, 5 de julio, 1986.
} 
la "parcelación" del trabajador, su mayor o menor grado de autonomía e iniciativa, etc.; en la empresa, la "iniciativa privada", respecto a sus múltiples interrelaciones con el poder y la sociedad; en las demás unidades económicas (cooperativas, mixtas, estatales, etc.); en el campo de acción de los frentes de masas, entidades ecologistas, feministas, etcétera.

Lo expuesto no pasa de ser un mero esbozo de algunas facetas o aspectos del enfoque metodológico, a nuestro juicio correcto, y cuyo sentido es la búsqueda, la aproximación constante, hacia lo concreto, en todos los espacios de la totalidad social del país respectivo.

Toda investigación sobre la democracia, según lo antes apuntado. implica indagar problemas como: el consenso y/o la coerción cotidianos; violación y/o respeto a los derechos humanos; las mediaciones, la negociación y el diálogo y/o la represión como métodos de solución de conflictos; la transparencia o el enmascaramiento del poder y sus múltiples prácticas; el ejercicio de la soberania en la toma de decisiones y prácticas estatales o gubernamentales o su hipertrofia o carencia (¿pero puede funcionar óptimamente la democracia en las semicolonias y neocolonias?); ${ }^{4}$ las relaciones hombre/mujer en todos los ámbitos. ${ }^{5}$

Por cierto que en la ofensiva actual contra el marxismo y el socialismo no es inocente la relevancia que proponen algunos politólogos y sociólogos de temas como la democracia y las instituciones o la cultura, en sustitución -es lo grave- de otros como la dependencia, las luchas sociales o la soberanía nacional. Algunos escriben, jubilosos, que el marxismo es un cadáver al que sólo hay que practicarle la autopsia. ${ }^{6}$

\footnotetext{
4 Nosotros venimos sosteniendo la tesis leniniana de que las colonias, semicolonias y neocolonias no pueden ser Estados nacionales en su sentido pleno. Más que Estados de la supuesta nación dependiente, se trata de poderes supeditados globalmente al imperialismo, condición que impide el florecimiento de la nación. Lenin planteó en el conocidisimo libro El imperialismo. fase superior del capiralismo, que en la época imperialista se configuraban naciones opresoras y oprimidas, en cuyos extremos se ubicaban los poderosos estados capitalistas coloniales y las colonias. Entre tales extremos se configura una variada gama de formas estatales dependientes. "Para esta época -escribió textualmenteson tipicos no sólo los dos grupos fundamentales de paises - los que poseen colonias y las colonias-, sino también las formas variadas de paises dependientes que desde un punto de vista formal, político, gozan de independencia, pero que en realidad se hallan envueltos en las redes de la dependencia financiera y diplomática. Una de estas formas, la semicolonia, la hemos indicado ya antes. Modelo de otra forma es, por ejemplo, Argentina. "Lenin, Obras escogidas en tres tomos, I, p. 762. En relación a tal planteamiento sostenía el politólogo boliviano ya fallecido; René Zavaleta Mercado, que tales ideas guías fueron abandonadas o no utilizadas por sociólogos y científicos sociales en general, y que abrían una excelente brecha teórica para- desarrollar múltiples problemas que afectan a las semicolonias y neocolonias. ¿Cómo calificaría Lenin la forma dependiente estatal de países como Honduras o El Salvador? La cuestión es que no puede omitirse el ejercicio de la soberania nacional, la libre autodeterminación o su ausencia, en la investigación sobre la democracia. ¿De qué tipo de democracia podemos discutir cuando en un país las decisiones esenciales, sin excepción, se toman por una potencia extranjera? ¿Cómo se puede tildar de democrático a un país intervenido en el que la fuerza militar imperial determina la vida y destino de la sociedad? La democracia implica necesariamente la libre determinación del pueblo. Son términos incompatibles democracia y colonia, protectorado o neocolonia. Véase el trabajo de Pablo A. Martínez, Democracia y soberanía nacional. Dos metas inseparables en el Caribe. El caso de República Dominicana. mimeo.

s"El grado de emancipación de la mujer en una sociedad es el barómetro natural por el que se mide la emancipación general". Saint-Simon, citado por F. Engels en Del socialismo utópico al socialismo científico.

'A título de ejemplo léase Ludolfo Paramio, "Tras el Diluvio: un ensayo de postmarxismo", Nexos, 109, enero, 1987; Luis Salazar C., "Marxismo y sociologia", en Sociológica
} 
La democracia como abstracción formal no existe. La democracia es siempre un movimiento político concreto impulsado y promovido por específicas fuerzas sociales de clase, que luchan por determinados objetivos. La democracia "sin adjetivos" no es tal por la simple razón de que la democracia es un concepto histórico y por consiguiente con contenidos de clase diversos: según el momento del desarrollo, nivel de avance de las fuerzas economicosociales, lucha de clases especifica, etcétera.

En la historia han tenido existencia real la democracia griega (esclavista), democracias municipales en la Edad Media, y otras. Con las revoluciones burguesas hace su aparición, como un movimiento real y con su correspondiente categoría, la democracia burguesa. Más concretamente, las grandes revoluciones anticapitalistas abrieron diversas vertientes reales y sus correspondientes conceptos de democracia: democracia liberal burguesa, democracia social, etc. Con los movimientos proletarios surge, en el siglo xix, la democracia proletaria o socialista. Aparece después la democracia popular. En todas las experiencias y categorías respectivas está presente el contenido de clase. Aclaremos: las dictaduras estalinistas no son, no han sido democracias socialistas. Pero tal problema concreto amerita tratamiento específico.

Así como no se puede hablar de la revolución en el movimiento real en abstracto, sino de revoluciones sociales concretas, con contenidos de clase específicos (revoluciones burguesas, socialistas, democrático-populares, democrático-nacionales...), la cuestión de la democracia debe plantearse en términos de qué fuerzas sociales son portadoras de ella y cómo se plantea su implantación.

No es casual que la concepción reduccionista de la democracia, entendiéndola como la sola fórmula parlamentaria junto con la célebre división de poderes y el respeto a determinados derechos humanos, sea propia de la democracia burguesa. Por su parte, la democracia socialista y la democracia popular han exigido formas originales de expresión y organización de la voluntad colectiva, inducidas no por postulados dogmáticos abstractos sino por la propia experiencia histórica. $^{7}$

Un autor, Enzo Faletto, escribe lo siguiente:

Si bien para la caracterización de la crisis, en términos de democracia-autoritarismo, es necesario particularizar el sentido de la dominación autoritaria, conviene, también, preguntarse por el signifi-

teoría sociológica, año I, núm. 1, Departamento de Sociologia, UAM-Azcapotzalco. Agustín Cueva refuta a los enterradores del materialismo histórico en varios trabajos. entre ellos los siguientes: Agustín Cueva, "El a nálisis postmarxista del Estado latinoamericano". ponencia ante el VII Congreso Centroamericano de Sociologia. Tegucigalpa, Honduras, 2-7 noviembre, 1986, mimeo. Véase "Entrevista a Agustín Cueva: ciencias sociales y marxismo en América Latina hoy", de José Luis Piñeyro, en la citada revista Sociológica. Agustín Cueva es el compilador de una serie de trabajos bajo el título "Tiempos conservadores: América latina en la derechización de Occidente". que publicará la revista $A$ de la UAM-Azcapotzalco. Ver especialmente en cuanto al tema la introducción y el artículo. ambos de Cueva, titulado el último: "El viraje conservador: señas y contraseñas". La revista Dialécrica publicará los trabajos presentados en el encuentro "Marxismo y Cultura Política"

${ }^{7}$ Pero el método correcto exige superar la hipótesis general o el calificativo general, en una aproximación constante hacia las expresiones concretas en todos los espacios concretos del todo social. 
cado concreto de la democracia en América Latina. La democracia implicaría la existencia de, por lo menos, un estado de derecho, de una forma de representación de mayorías y minorías, de un régimen de partidos políticos y, fundamentalmente, de un conjunto de garantías ciudadanas. ${ }^{8}$

Como es obvio, la categoría de democracia que plantea el autor citado para el análisis de la problemática latinoamericana no rebasa los linderos de la democracia burguesa representativa o formal. Tal concepción es superestructuralista. En ella no entra la índole de la estructura socioeconómica, la naturaleza de la propiedad de los medios e instrumentos de producción. Posiblemente, desde las perspectivas de los países capitalistas desarrollados, una concepción superestructuralista de la democracia sea idónea. Pero en aquellos paises capitalistas dependientes, sumamente atrasados, como los de Centroamérica, se establece un nexo indisoluble entre lo superestructural y lo estructural, que debe comprenderse en la categoría democracia. ¿Qué sentido tiene pensar en Centroamérica o el Caribe -igual que en muchos países del Tercer Mundo- en una democracia que no satisface las necesidades "primarias" o "básicas" de las masas populares?

Tenemos presente que en países de capitalismo desarrollado, como los de Europa occidental, Japón o Estados Unidos, no se precisa, tal vez, de una recomposición radical de las estructuras económicosociales para lograr la cobertura de las "necesidades básicas y prioritarias", esto es: el derecho a la vida misma y a la paz, la alimentación adecuada, el trabajo asegurado y justamente remunerado, la vivienda decorosa, la educación en todos los niveles y la salud. Pero en la periferia capitalista del mundo, en donde las cifras de mortalidad y natalidad infantil, hambre, desnutrición, muerte prematura, analfabetismo, condiciones zoológicas en cuanto a vivienda, etc., alarman constantemente en foros internacionales y aun en los medios de comunicación de masas cotidianos, la situación es radicalmente diferente.

Aquí la democracia, el régimen político, debe asumir estas carencias. Y por ello la democracia (recordemos que su etimología es "poder del pueblo") debe garantizarle a ese pueblo, es decir a las mayorias, a las masas, el mínimo de condiciones dignas del ser humano. $Y$ debe garantizárselo en la realidad, no en la simple letra de constituciones o leyes que jamás se escriben o cumplen.

Por ello reafirmamos el nexo indisoluble entre el aspecto superestructural de la democracia, en el cual debe estar presente indiscutiblemente el elemento representatividad, y la estructura socioeconómica. Planteémoslo con más claridad: el proyecto democrático en países atrasados, en los que la obsolescencia de las estructuras económicas y sociales es la característica sobresaliente, considera, necesariamente, la transformación profunda de la sociedad. Aquí entra en juego la indole del sistema económico y consecuentemente la naturaleza de la propiedad de los medios e instrumentos de producción. ${ }^{9}$ Las alternativas históricas parecen ser el socialismo y su particular

${ }^{8}$ Enzo Faletto, "Estilos alternativos de desarrollo y opciones politicas. Papel del movimiento popular": América Latina: desarrollo y perspectivas democráticas, San José, Flacso, p. 106

${ }^{9}$ El rescate de la soberania nacional, el ejercicio real de la autodeterminación, se torna exigencia consustancial del régimen democrático. 
tipo de poder democrático y la economía democrătico-popular, apoyada en un fuerte sector estatal de la economía, con su sistema de democracia popular. El ejemplo típico es Nicaragua.

Ciertamente los gobernantes de Estados Unidos han contemplado, en algunas ocasiones, la necesidad de que se efectúen reformas estructurales en América Latina: traigamos a la memoria el Plan de la Alianza para el Progreso, y en los últimos tiempos - durante la administración Reagan - el proyecto de una reforma agraria sui generis, impuesto a los mismos jefes del ejército salvadoreño. El famoso Informe Kissinger, por cierto, replantea, con mayor visión de futuro, la necesidad de desarrollar la región centroamericana, generando entre otras medidas, reformas estructurales. Pero el problema es que el concepto de democracia, manejado por los imperialistas de todo color, se basta a sí mismo con ingredientes puramente formales. Ejemplos recientes, las elecciones en El Salvador, Honduras y Guatemala.

Por otra parte, y siguiendo el hilo de lo que antes exponíamos, cabe señalar que ciertas reivindicaciones que aparecen en la lucha revolucionaria en Centroamérica (alimentación, trabajo, salud, educación, vivienda, etc.), y que en los países desarrollados del capitalismo han sido cubiertas en lo esencial desde hace décadas, en el contexto regional surgen con un cariz subversivo y se presentan como planteamientos de tipo revolucionario, debido al marco de miseria, atraso y opresión que les sirve de entorno.

Por todo lo expuesto consideramos que una caracterización de la democracia como la que nos propone Faletto, ${ }^{10}$ al indagar sobre el significado de la misma para América Latina, no corresponde a los procesos de liberación nacional y social de los pueblos y por lo tanto, se convierte en material especulativo, poco útil al científico social o al político ubicado en el campo popular revolucionario.

Partiendo de la premisa científica de que no existe la democracia "sin adjetivos" o la democracia "en general", estimamos que el concepto útil para el análisis de procesos y estructuras en América Latina es el de democracia popular. Se trata de un concepto no exclusivamente superestructuralista sino totalizante, que comprende a la sociedad como totalidad.

La realidad presente de América Latina y el Caribe ofrece, en general, el muestrario de una serie de insatisfacciones de los pueblos que debe ser asumido por el régimen de democracia popular. Veamos:

- Insatisfacción por la distribución del ingreso tanto nacional como internacional.

- Insatisfacción respecto a la cobertura real de necesidades colectivas básicas y prioritarias (alimentación, trabajo, vivienda, educación, salud, etcétera).

- Insatisfacción respecto a las tasas de ocupación.

- Insatisfacción derivada del derroche por consumismo, armamentismo, corrupción, burocratismo, etcétera.

- Insatisfacción derivada de la falta de respeto a los derechos humanos en general.

- Insatisfacción respecto a las formas de la relación entre la masa trabajadora y el Estado y entre la ciudadanía y el mencionado. Estado.

${ }^{10} \mathrm{El}$ concepto de Faletto es el comúnmente aceptado por los científicos sociales y en las academias de Latinoamérica. 
En esta linea de pensamiento se inscribe un concepto de democracia expuesto por el comandante de la revolución nicaragüense, Carlos Núñez. En tal concepto aparecen como requisitos especiales:

El régimen económico asegura a hombres y mujeres sus necesidades básicas de alimento, trabajo, vivienda, educación y salud.

Las instituciones gubernamentales están vertebradas para acortar la distancia y hacer fluida la comunicación entre el aparato de poder y las mayorías populares.

El gobierno hace descansar la defensa del poder popular sobre todo el pueblo en armas.

Se logra la participación popular organizada para la realización de los planes económicos, políticos y sociales.

Existe la voluntad política, la legislación y los mecanismos para hacer efectivos y garantizar los derechos políticos, sociales y culturales de las mayorias.

El poder está determinado por las masas trabajadoras cuyo sello es netamente popular. ${ }^{11}$

El nicaragüense Núñez nos ofrece un concepto, más o menos completo, de la democracia popular. En tal categoría está implícita tanto la superestructura como la estructura de la sociedad. Deseamos subrayar que el elemento "representatividad" está comprendido en la categoria. A la cuestión de la "representatividad" nos referimos adelante, con bastante detalle, sobre todo en relación al sistema de Nicaragua revolucionaria.

En Centroamérica - y quizás en América Latina y el Caribe- se enfrentan dos concepciones clasistas de democracia. Intentaremos dibujar los contornos de la democracia que el imperialismo norteamericano esgrime y lucha por imponer en nuestra América. La democracia como estereotipo de los imperialistas, y sus aliados locales, es aquella que reúne algunas condiciones mínimas:

1. El régimen tiene que ser resultado de elecciones generales. Se excluyen aquellos gobiernos que surgen de una insurrección popular o una guerra revolucionaria.

2. Respeto a la propiedad privada y a las inversiones extranjeras. Se excluyen las nacionalizaciones y socializaciones como política estatal.

3. Respeto absoluto a la libertad de prensa y de información, basada en la libertad de empresa sin restricciones y orientada por el criterio ideológico que manejan las agencias informativas del imperialismo o transnacionales de la información, sin importar - todo lo contrario- si tales o cuales medios de comunicación de masas sirven o no a la contrarrevolución o al imperio dominador.

4. Pluralismo político e ideológico absoluto. Se incluye el respeto a las organizaciones y tendencias político-ideológicas contrarias a la revolución y favorables al imperialismo.

5. Sometimiento a las normas de política exterior del imperialismo.

"Carlos Núñez, "El reto democrático en Centroamérica", San José, Departamento Ecumérico de Comunicación, p. 166. Valioso aporte al debate en torno a la democracia en el reciente libro de Orlando Núñez y Roger Burbach titulado Democracia y revolución en las Américas. México, Edit. Nuestro Tiempo, 1988. 
En consecuencia, quedan proscritas las políticas de solidaridad, ayuda y cooperación con otros países, especialmente los socialistas. Se prohíben las políticas de no alineamiento y las que tiendan a establecer lazos fraternales de amistad y cooperación con los países socialistas.

6. El gobierno, en fin, no debe estar en manos de socialistas, ni aun cuando ello se deba a sus exigidas elecciones generales (caso de Chile). Tampoco debe estar en manos de dirigentes de guerras populares o luchas caracterizados como marxistas. Los casos de Chile y Nicaragua y las respectivas políticas de Estados Unidos son aleccionadoras al respecto.

Es decir que el imperialismo norteamericano no acepta, ni siquiera, su democracia capitalista formal cuando las mayorías eligen gobernantes socialistas o marxistas. La democracia burguesa de Costa Rica ha sido respetada hasta hoy, porque el sistema de ese país favorece los designios y políticas de Estados Unidos.

En Centroamérica se está configurando un tipo de democracia popular que indudablemente es resultado de procesos de guerra revolucionaria, de la lucha armada como forma principal de la revolución. Los esquemas, que resultaron obsoletos y que manejaron las izquierdas centroamericanas durante décadas, fueron superados. Los frentes populares revolucionarios - unión de obreros, campesinos, artesanos, mujeres, estudiantes, etc., en un nuevo sujeto revolucionario: el pueblo- descartaron la vieja concepción de las dos revoluciones (la burguesa democrática y la socialista) y configuraron en la realidad, como en Nicaragua, y en los proyectos, como en .El Salvador y Guatemala, no la conformación de sociedades socialistas y poderes políticos socialistas sino la de sistemas democrático-populares, con sus regímenes de democracia popular.

¿Es tal democracia popular un régimen de transición hacia el socialismo? Pensamos que sí. Estas y muchas otras interrogantes ligadas con la índole de las fuerzas políticas y sociales que portan el nuevo sistema, con la hegemonia en el proceso, con las cuestiones de la transición, etc., son temas que, pensamos, deben debatirse.

Las revoluciones centroamericanas son democrático-populares, antiimperialistas y antioligárquicas. El régimen democrático popular, como en Nicaragua, tiene que cumplir tareas no resueltas por las burguesías, como la cuestión de la soberanía nacional, la reforma agraria y otras de igual índole. Pero el régimen no se detiene en las reformas o cumplimiento de tareas que debieron haber cumplido las clases periclitadas sino que va más allá: pone los cimientos de una nueva sociedad más humana y digna. Tal pareciera que los revolucionarios centroamericanos se han inspirado en aquel hermoso postulado de la Declaración de Independencia de los Estados Unidos que reza que existe el "derecho de abolir el gobierno que no garantice al pueblo la felicidad". 12

\footnotetext{
:". Sostenemos como verdades evidentes que todos los hombres nacen iguales, que están dotados por su Creador de ciertos derechos inalienables, entre los cuales están el derecho a la Vida. a la Libertad y a la consecución de la Felicidad; que, para asegurar estos derechos, los hombres instituyen gobiernos, derivando sus justos poderes del consentimiento de los gobernados: que cuando una forma de gobierno llega a ser destructora de estos fines. es un derecho del pueblo cambiarla o abolirla, e instituir un nuevo gobierno, basado en esos principios y organizando su autoridad en la fo:ma que el pueblo estime como la más conveniente para obtener su seguridad y felicidad". De la Declaración de Independencia de Estados Unidos de América. el 4 de julio de 1776.
} 
Pueblos enfrentados a dictaduras de varias décadas luchan con las banderas de la democracia en alto y en el conflicto tropiezan con el propio imperialismo norteamericano, interiorizado en la formación social, y desde luego con los grupos oligárquicos usufructuantes del sistema. Asi, el carácter democrático de tales movimientos, en que las propias masas son el protagonista principal, se constituye en uno de los elementos esenciales del nuevo régimen. Son movimientos populares en el más correcto sentido del término los que a través de la lucha armada logran instalar la democracia que ya no puede limitarse al contenido de la burguesa.

En la democracia popular está implícito, lógicamente, el respeto a los derechos humanos. Pero esta cuestión tampoco es ajena a la lucha de clases.

Los derechos humanos surgen como declaraciones de la burguesia, con un signo marcadamente individualista, arremetiendo contra concepciones y estructuras feudales. En el siglo xvin aparecen la Declaración de Derechos del Hombre y del Ciudadano de la Francia revolucionaria y las declaraciones de las excolonias británicas en Norteamérica. Con las revoluciones proletarias y Lenin se postula la Declaración de Derechos de los Pueblos Explotados y Oprimidos.

En el presente son muchas las declaraciones de derechos. Entre las más significativas y reconocidas internacionalmente se encuentran la Declaración Universal de Derechos Humanos de 1948, el Pacto Internacional de Derechos Económicos, Sociales y Culturales de 1966, la Declaración Universal de los Derechos de los Pueblos o Declaración de Argel de 1976, la Declaración Americana de los Derechos y Deberes del Hombre o Declaración de Bogotá de 1948, la Convención Americana sobre Derechos Humanos de 1969.

Los voceros e ideólogos de la democracia burguesa ponen el énfasis en los derechos humanos marcadamente individualistas, como el de libre expresión del pensamiento, el derecho a disentir o los derechos políticos del ciudadano ante el Estado. Todavía resuenan los ecos de los escándalos ideológico-publicitarios en torno a intelectuales cubanos, relacionados con la violación del derecho a la libre expresión del pensamiento o del derecho a disentir, derechos caros a las elites intelectuales de todo el mundo. Queremos significar que tales sucesos son objeto de una encarnizada lucha ideológica de clases. La desproporción del ruido organizado y manipulado, en tales ocasiones, en un continente en que cifras inauditas de niños se mueren de hambre y decenas de miles de hombres y mujeres son asesinados y desaparecidos, para citar dos tipos de fenómenos cotidianos en América Latina, es elocuente.

Nos interesa subrayar el hecho de que al imperialismo norteamericano y a las clases burguesas dependientes, jamás les ha preocupado hacer realidad, para las masas, los llamados "derechos colectivos de los pueblos" o "derechos económicos, sociales y culturales". Ni tampoco los derechos humanos del "individuo". Apuntemos la incapacidad evidente de las pocas democracias formales que han funcionado en Latinoamérica para lograr, realmente, la cobertura para las masas trabajadoras de tales derechos "económicos, sociales y culturales", esto es, los derechos a la vida, a la alimentación adecuada, al trabajo seguro, a la salud integral, a la vivienda digna, a la educación y a la cultura.

Por otra parte, los gobiernos despóticos, del tipo de los que han 
abundado en Centroamérica, han violado y permitido la violación de todos los derechos humanos, incluidos los individuales, particularmente cuando las víctimas son de las clases explotadas y oprimidas y grupos marginados, es decir de las masas trabajadoras. De tal manera que en la propia necesidad vital de los pueblos centroamericanos se insertan los derechos humanos y su respeto en la realidad.

Nosotros pensamos, desde la perspectiva de los pueblos oprimidos, miserables y atrasados de la periferia mundial, que los derechos prioritarios son los de los pueblos, los de las masas trabajadoras, a la paz en primer término y a la autodeterminación libre en segundo. Después vendrían aquellos derechos "colectivos" que atañen directamente a una vida digna del hombre, con pleno acceso a los bienes materiales y culturales producidos hasta hoy por la humanidad.

El derecho a la revolución ha sido postulado en casi todas las declaraciones. En la Francia. revolucionaria de 1789 aparece como “derecho de resistencia a la opresión". En la Declaración de Independencia norteamericana el espíritu de la norma es más ambicioso. Es el derecho del pueblo "a abolir el gobierno que no le garantice la felicidad". El derecho a la rebelión o a la revolución de los pueblos centroamericanos, íntimamente ligado a la libre autodeterminación, está reconocido por la conciencia jurídica universal y por la tabla de valores dominante en el mundo. Claro está, el imperialismo norteamericano demuestra a diario el criterio de que tales valores y principios jurídicos favorables a los pueblos no pasan de ser sandeces en un mundo manejado por los poderosos. Pero es ostensible la legitimidad histórica de las formas resultantes de la rebelión popular.

Para concluir esta parte queremos recordar que en Centroamérica, con la excepción de Costa Rica, la misma democracia burguesa formal con su respeto a los derechos humanos ha sido una planta exótica. Esta cuestión, como antes apuntamos, en pocas ocasiones ha preocupado a los hoy celosos gobernantes de Estados Unidos ante el destino de Centroamérica.

El tema de la democracia en Centroamérica se convierte inmediatamente en el de "la lucha por la democracia".

Hace más de cinco años podía afirmarse que las repúblicas centroamericanas seguían siendo, con la consabida excepción de Costa Rica, las tradicionales dictaduras militares, con matices propios en cada país. Ahora la situación es distinta.

Hagamos un brevísimo recorrido por las líneas sustanciales de la historia de estos países. Partimos de la existencia de particularidades muy hondas en cada proceso. No obstante, hay ingredientes que les otorgan generalidad tanto a la matriz económica como a la superestructura política. Hay, pues, elementos esenciales comunes.

En Guatemala y El Salvador se consuman en el siglo pasado las llamadas "revoluciones liberales". Se trata de procesos profundos de expropiación, en especial de la tierra, acompañados de mucha violencia. Su significado más importante y último es la "liberación" de la tierra y la fuerza de trabajo. El resultado es el aparecimiento del capitalismo agrario a través de un producto de exportación. El modo capitalista de producción se convierte en dominante, conjugado con secuelas precapitalistas como los trabajos forzados y formas de producción no capitalistas subsumidas en el sistema. Estos procesos determinan y condicionan el surgimiento de grupos dominantes configuradores de oligarquias y de un poder político acorde con el atraso global 
de la sociedad, de naturaleza despótico, totalmente antidemocrático. ¿Pero era posible hacer que funcionase la democracia formal burguesa en semejante rezago histórico?

El Estado oligárquico, profundamente despótico, es el que se expresa en las tiranias clásicas de Guatemala y en los regimenes de fuerza que concluyen en El Salvador con la dictadura militar inaugurada en 1932 y que llega al presente. La historia de Guatemala y El Salvador es la historia de la violencia. De una violencia que penetra todo el tejido social (relaciones de producción, relaciones con el poder, etc.); sociedad politica y sociedad civil impregnadas de violencia. Sobre los cimientos de una débil y fragmentada estructura comienza a formarse una clase dominante que irradia su dominación por medio de la coerción y no de un proyecto hegemónico. Burguesía incompleta, no acabada y Estado privatizado, tampoco acabado, en el sentido del Estado moderno o burgués. Tal parece que es el Estado el configurador de la clase oligárquica en forma tal que la sociedad civil siempre está subsumida o aherrojada, siendo incapaz, por tanto, de desarrollar un proyecto hegemónico de dominación apoyado en el consenso. A la imposibilidad de la clase dominante de armar su sistema de dominación, con hegemonía, ha correspondido el autoritarismo rampante como práctica política esencial.

Para agravar la situación se consolidaría, en su momento, un mecanismo de sujeción y dependencia, de índole económica, política, militar, ideológico-cultural, etc., respecto a Estados Unidos. En fin, el Estado concluyó por ser, en su más profunda esencia, oligárquico marcadamente despótico y neocolonial.

La excepción al trazo genérico anterior está constituida por los regímenes guatemaltecos de la llamada Revolución de Octubre, que sólo duraron diez años.

Honduras y Nicaragua nos muestran algunas particularidades por comparación con Guatemala y El Salvador. Mayor incidencia y repercusión de las guerras civiles; vastas extensiones territoriales despobladas; incomunicación interna; muy débil y casi nula articulación social y cohesión "nacional"; mayor rezago histórico, etc. En estos países, con su particular historia cada uno, no se constituyen economías sólidas.

Se forman oligarquías tradicionales de base terrateniente. Las reformas equivalentes a las "revoluciones liberales" de Guatemala y El Salvador fueron en estos países intentos tardios y en buena medida frustrados. El capitalismo agrario fue posterior y de forma dispersa y fragmentaria.

Nicaragua será pronto la presa codiciada por el imperialismo, que se propone utilizar su excelente posición geográfica y sus lagos para impulsar el tránsito interoceánico. Este fenómeno sellará su destino, primero con las intervenciones y ocupación armada de la marinería yanqui y después con la instalación de un régimen de fuerza hecho a imagen y semejanza de la brutal política norteamericana. Nos referimos al especial sistema político somocista.

En Honduras, el país más atrasado del área, ante la ausencia de una clase dominante oligárquica -como en Guatemala y El Salvador - capaz de iniciar la organización del Estado y la configuración de la nación, lo hacen las compañías extranjeras. El plátano es el producto que vincula el país al mercado mundial, pero lo hace obstaculizando toda perspectiva de promover el mercado nacional, la nación 
y el Estado nacional. El enclave frutero constituye un "Estado dentro del Estado". Si la debilidad estructural, en El Salvador y Guatemala, determinó la existencia de burguesías incompletas, aquí la propia existencia de una clase burguesa dominante queda obnubilada ante la presencia de poderosos factores externos. La propia estructura económica se integra a la economía norteamericana, de espaldas a la nación en perspectiva. La dependencia y sujeción, respecto al imperialismo norteamericano, son los más fuertes de la región. El proceso obstruye la formación de un mercado realmente nacional y frustra el proyecto del Estado-nación, más que en los demás países. Tales condiciones objetivas son obstáculos a la unificación político-nacional y favorecen las pugnas de caudillos y las revueltas locales. Las compañias fruteras obtienen ventajas leoninas de tales pugnas y revueltas y se imponen como poder decisorio.

En un país con las condiciones objetivas esbozadas era utópico pensar en la vigencia de la democracia representativa burguesa. Lo que ha predominado son regímenes de fuerza, con alguna excepción, que en esencia son débiles ante el poder de las compañías fruteras y del propio imperialismo y se apoyan en el estamento militar. El papel que juega actualmente Honduras como plataforma contrarrevolucionaria del imperialismo, en indignas condiciones de sumisión colonial, no es ajeno, lógicamente, a todo lo expuesto.

De la rápiḍa revisión que hemos realizado sobre la historia de estos cuatro países centroamericanos concluimos que, supèrestructuralmente, el resultado ha sido la constitución de regímenes antidemocráticos, de marcado autoritarismo, con prácticas generales despóticas.

Costa Rica es la excepción por antonomasia. La transición al capitalismo agrario fue evolutiva, no violenta. La escasa población criolla se asentó en la meseta central en tanto los indígenas se refugiaron en el interior. Una población reducida inició la producción de café para exportarlo, muy temprano en el siglo pasado. Con cuatro décadas de adelanto sobre Guatemala y El Salvador se adoptó una política de reparto pacífico y legal de tierras y de promoción de la cafeticultura.

En Costa Rica no se acude a métodos violentos de expropiación, como en Guatemala y El Salvador, y, en forma menos relevante, en Nicaragua y Honduras. Las condiciones objetivas no son propicias para los irabajos forzados, como en Guatemala. La ausencia de guerras civiles cimenta un clima de paz. La economía capitalista cafetalera se desarrolla con base en la propiedad familiar pequeña y mediana. En coherencia con tales estructuras productivas, en que la violencia no tiene función esencial alguna, surgirán unas instituciones políticas democráticas de origen campesino.

La democracia representativa formal, predominante en el país en el presente siglo, encuentra sus raíces históricas en aquellas particulares relaciones de producción apoyadas en el consenso y no en la coerción. La explicación de la democracia burguesa, como forma dominante en Costa Rica, requiere mayor abundamiento de información, que por su índole no podemos suministrar en este trabajo. El resultado es que Costa Rica, pese a la grave crisis económica que sufre y a la crisis política de la región, continúa aún, casi al borde del precipicio, viviendo una democracia capitalista formal, a diferencia de los otros paises.

Escribimos antes que la situación presente en Centroamérica es heterogénea. En efecto, al lado de férreas dictaduras militares en El 
Salvador (pese a los velos electoraloides) y Guatemala. ${ }^{13}$ y un régimen cuasicolonial y antidemocrático en Honduras (aunque haya sido precedido de elecciones generales), se encuentra Costa Rica funcionando, en condiciones cada vez más dificiles y amenazada por el militarismo, como una democracia burguesa o formal, en tanto que Nicaragua es, desde julio de 1979, una democracia popular.

Nos parece obvio que la democracia por la cual luchan los pueblos en El Salvador, Guatemala y Nicaragua es la democracia popular. Respecto al concepto de democracia popular, antes manifestamos que hacíamos nuestro el expuesto por el nicaragüense Carlos Núñez. A riesgo de parecer cansinos por la reiteración, expongamos, de nuevo, las condiciones de la democracia popular que está surgiendo en Centroamérica.

1. El régimen económico asegura a hombres y mujeres sus necesidades básicas de alimentación, trabajo, vivienda, educación y salud.

Lo prioritario es que el régimen asegure realmente (no sólo en las constituciones y otras leyes) la cobertura de las necesidades básicas de las masas. Aquellas necesidades que el capitalismo desarrollado logró cubrir en general, pero que en la periferia del capitalismo se convierten en derechos prioritarios y motivos de subversión y lucha despiadada. No puede ser aspiración de los pueblos salvadoreño o guatemalteco, por ejemplo, una democracia con hambre o una democracia con analfabetos o una democracia de desnutridos, enfermos y desocupados. Por ello nos parece que la democracia en los pueblos del más pavoroso atraso, como son la casi totalidad de los del llamado Tercer Mundo, los de América Latina, digámoslo de una vez, debe ser capaz de asegurar a los seres humanos condiciones de vida dignas del hombre, dejando atrás las circunstancias zoológicas en que se debaten las grandes mayorías de la periferia mundial. En términos de derechos humanos -y considerando a éstos como elemento esencial del sistema de democracia popular - pensamos que, sin negar la importancia del respeto a los derechos individuales, la prioridad la tiene la efectividad o cumplimiento real de los derechos llamados "económicos, sociales y culturales de los pueblos". Hasta el momento, ello es evidente, las pálidas democracias burguesas o formales de Latinoamérica no han logrado que tales derechos puedan ser efectivos para las masas populares. $Y$ es obvio, también, en el otro polo, que un país socialista como Cuba sí ha hecho realidad que la población trabajadora en su totalidad tenga asegurada su alimentación, trabajo, salud, educación y cultura, etcétera.

2. Las instituciones gubernamentales están vertebradas para acortar la distancia y hacer fluida la comunicación entre el aparato de poder $y$ las mayorias populares.

Es una realidad que el Estado capitalista contiene un aparato de poder distanciado, divorciado y hostil a las masas trabajadoras. En Centroamérica el Estado ha sido un poder "privatizado" y vinculado por miles de hilos visibles e invisibles a las familias oligárquicas, en

\footnotetext{
${ }^{13}$ Con el régimen de Vinicio Cerezo tal caracterización merece matizarse. Nos es imposible tratar siquiera someramente la situación.
} 
tanto que en relación a la masa de productores directos se presentó siempre como ajeno, lejano y hostil. Por el contrario, la democracia popular rompe con ese divorcio y distanciamiento y acerca, lo más posible, al pueblo trabajador y al funcionariado del Estado. La lucha en un régimen de democracia popular, como en Nicaragua, es contra todo burocratismo y secuela de "excrecencias parasitarias", por el otro de la fusión de los productores directos con el Estado. Hacer de los productores directos los dirigentes del Estado es el ideal. Lo primero es realizar una fluida comunicación entre dirigentes, gobernantes y funcionarios, por una parte, y los obreros, campesinos, artesanos, estudiantes, mujeres, por la otra.

3. El gobierno hace descansar la defensa del poder popular sobre todo el pueblo en armas.

Es un hecho que deslumbra por su claridad el que la mejor prueba de que un régimen cuenta con el respaldo popular es el de que el propio pueblo, las masas, esté armado. La construcción de la nueva democracia sobre las cenizas de la dictadura pasa por el camino de la revolución social. Las propias masas, en los combates liberadores, se ganan el derecho a defender con las armas en la mano sus conquistas. Pero esto sólo lo pueden hacer poderes revolucionarios socialistas o democracias populares resultantes de una revolución a través de la insurrección y la guerra popular. Con razón se dice que cuando un pueblo triunfa en una revolución por medio de las armas, tal triunfo equivale a un plebiscito o a una consulta electoral, en el que las masas, nítidamente, y sin los subterfugios ideológicos propios de las campañas electorales ordinarias, expresan su voluntad. Éstas no son frases: son hechos que se observan en Cuba y en Nicaragua, para mencionar dos ejemplos.

4. Existe participación popular organizada para la realización de los planes económicos, políticos y sociales.

Dos elementos esenciales importantes son la participación organizada del pueblo y la planificación económica, política y social. La planificación, que brilla por su ausencia en la democracia burguesa, es decisiva para el avance de la sociedad. Se supera la anarquía económica y social, propia del capitalismo y de la democracia formal burguesa. Las gestiones estatales y económicas se realizan actuando de consuno con organizaciones del pueblo en sindicatos, cooperativas, combinados económicos, poderes locales, unidades de producción, etc. Y decir pueblo organizado es entender implícitamente el funcionamiento de la representatividad mediante elecciones. En el caso de Nicaragua, tal representatividad a base de elecciones en los sindicatos, las fábricas, las unidades agricolas, las asociaciones de mujeres, las organizaciones de jóvenes, ha funcionado sin necesidad de las elecciones generales exigidas con fines contrarrevolucionarios por el imperialismo y la reacción interna. Adelante nos referiremos más a la cuestión de la representatividad en un régimen revolucionario.

5. Existe la voluntad política, la legislación y los mecanismos para hacer efectivos y garantizar los derechos políticos, sociales y culturales de las mayorías. 
La voluntad política de que trata el texto transcrito jamás se refleja en los gobiernos dictatoriales y muy rara vez en las excepcionales democracias burguesas del continente. Pero hay más: no sólo basta la voluntad politica sino que es imprescindible sentar los fundamentos que hacen posible la efectividad de los derechos políticos, sociales y culturales de las mayorías. Entre esos fundamentos destaca, en el caso de Nicaragua, el sector estatal de la economía creado por el poder popular. El área de propiedad del pueblo hace posible, en conjugación con el hecho irrenunciable de que el poder del pueblo es el que decide las reglas del juego, hace posible, repetimos, lo que se vuelve utópico en las democracias burguesas como la de Costa Rica y con mayor razón en las tiranías militares.

\section{El poder está determinado por las masas trabajadoras cuyo sello es netamente popular.}

A la inversa de lo que ocurre en los países capitalistas en los que la indole burguesa, elitista, es marca indeleble, en las democracias populares el signo que define la naturaleza del régimen es el de servir ante todo y sobre todo al pueblo trabajador, a las masas que son la inmensa mayoría de la población. No vacilamos en considerar que el sistema nicaragüense sandinista satisface tal exigencia.

En este trabajo sostenemos que el proyecto de los movimientos revolucionarios de El Salvador y Guatemala pretende, cuando menos, implantar y consolidar una democracia popular y que en Nicaragua ésta es realidad desde el 19 de julio de 1979.

Hay en Centroamérica, pues, dos concepciones de democracia que se enfrentan, concepciones antagónicas - y a la vez expresión- de la lucha de clases. Una es la democracia formal burguesa que funciona en Costa Rica y otra es la democracia popular que vive Nicaragua y por la cual luchan los pueblos de Guatemala y El Salvador. La "democracia" con que pretende el imperialismo maquillar la dictadura militar en El Salvador, mediante elecciones, no es otra cosa que el resultado de las maniobras. intervencionistas de Estados Unidos. El régimen actual de El Salvador no pasa de ser un instrumento de indole colonial, totalmente antidemocrático, al servicio de la política imperialista. El gobierno de Honduras, resultante de elecciones generales, también es en su esencia un instrumento de indole colonial al servicio de Estados Unidos. $Y$ es obvio: no se puede ser colonia y al mismo tiempo pretender que se vive una democracia.

El triunfo del 9 de julio de 1979 en Nicaragua es el triunfo de un movimiento democrático popular. Ciertamente no es el triunfo de un movimiento democrático popular por métodos electorales. Ser el resultado del martirologio y la lucha armada de un pueblo harto de opresión confiere mayor legitimidad histórica a la democraciannicaragüense. Elecciones generales las hubo durante el largo periodo del régimen de los Somoza. Y la índole despótica, antidemocrática del sistema, no varió. Claro es, la Nicaragua somocista jamás operó como democracia burguesa.

Las elecciones generales de Nicaragua consolidarán la revolución. Bienvenidas sean. ${ }^{14}$ Pero queremos destacar que ese país no ha necesi- 
tado la práctica de elecciones generales - que comenzó a exigir la reacción interna y el imperialismo desde el momento del triunfopara poder ser caracterizado como una democracia. La democracia popular no requiere determinadas fórmulas estereotipadas para ser tal. Los procesos democrático-populares, revolucionarios, van estructurando su propia armazón democrática sobre la marcha, incluso desde mucho antes del triunfo. El problema de la representatividad se plantea desde un ángulo diferente del de la democracia capitalista. Las elecciones generales son importantes, pero están determinadas por el proceso revolucionario.

Actualmente, en El Salvador, funcionan los llamados poderes populares en las zonas controladas por las fuerzas revolucionarias. Y estos poderes populares son embriones de democracia popular, desde su estructura económica hasta los métodos de distribución, desde las escuelas primarias hasta la organización de los servicios de salud. Los poderes populares de El Salvador son a la vez embriones de lo que es posible llegue a constituir el nuevo Estado salvadoreño, el Estado popular revolucionario.

Elemento esencial de todo régimen democrático es la representatividad. No es gratuito que la democracia formal se adjetivase a sí misma como representativa, a tal grado que democracia burguesa y democracia representativa llegaron a ser sinónimos. Pero el problema de la representatividad no es simple. No tiene que ser la misma problemática en una democracia formal que en una democracia popular. ¿Por qué vamos a caer en la trampa de la hermenéutica burguesa de considerar sólo representativos a aquellos miembros de la burocracia estatal que son tales a consecuencia de elecciones generales? Por otra parte, hay elecciones generales y elecciones generales. Todos los regímenes militares tiránicos de Centroamérica, el Caribe y el sur del continente han celebrado elecciones generales, que no constituían más que gigantescos fraudes e imposiciones brutales, acompañadas de verdaderos genocidios. De hecho las elecciones generales (no es el caso de países capitalistas desarrollados como Francia, Italia o la misma España) están bastante desacreditadas en muchos pueblos latinoamericanos y caribeños. Pero de cualquier manera, reafirmamos que la representatividad es un ingrediente de la democracia, sea formal Burguesa o popular.

Recordemos que en la tradición de la revolución proletaria mundial, la representatividad funcionó en la práctica y fue asumida por la teoría. El propio Lenin insistió sobre tal punto. Es mảs, fueron las revoluciones proletarias o socialistas las que introdujeron, a la par que las elecciones, el derecho a la revocación de los funcionarios electos. La representatividad democrática proletaria es intrínseca al socialismo y al marxismo. ${ }^{15}$

La ciencia política burguesa ha insistido en elecciones democráticas para jefe de Estado, diputados, etc. Pero ha descuidado aspectos esencialesade un real sistema democrático. Por más elecciones generales que se practiquen en los países capitalistas, jamás superarán el clima antidemocrático, "cuaftelario, de la fábrica, en la que opera el despotismo fabril ubicado en el polo del capital. La parcelación o mutilación física y espiritual del productor directo, y la disciplina despótica de la unidad productiva, jamas la podrá superar, reiteramos, el sistema capitalista. Nosotros queremos llamar la atención sobre que la cuestión de los

${ }^{15}$ Otro fenómeno es que verdaderos despotismos de tipo colectivista estaliniano hayan pretendido pasar por democracias socialistas. Lo comprueban los interesantes procesos de reformas como el de Gorbachev. 
procedimientos electorales y el derecho a revocar el mandato que les asiste a los electores, en la democracia popular, asume importancia vital en el interior de la fábrica o la unidad productiva en general, en el sindicato, en los poderes locales, en las asociaciones de la masa popular organizada (asociaciones de jóvenes, de estudiantes, de mujeres, de comités de defensa de la revolución, etc.). Estas formas de representatividad, minusvaluadas por los apologistas de la democracia formal, tienen una importancia igual, si no mayor, para la masa de productores directos, que las célebres elecciones generales. Éstas a menudo se convierten en el simple método de sustituir hombres que continúan haciendo funcionar sistemas totalmente antidemocráticos, en su más profunda esencia. Junta que administra los negocios comunes de la burguesía en su totalidad, llamó Marx a los gobiernos, resultantes de elecciones generales o no, de los países capitalistas. Vale la pena reflexionar, aún hoy, sobre la gran dosis de verdad que contiene tal tesis, para poder evaluar, en su exacto significado, las elecciones generales sobre las que tanto parlotean los ideólogos del imperialismo y la reacción interna.

En cuanto a Nicaragua, el hecho de que el nuevo poder político sea resultado de una guerra popular, combinada con la insurrección de las masas, otorga un sello especial al problema de la mecánica del sufragio general y toda esa parafernalia que enarbola la contrarrevolución local y el imperialismo. Se trata de ese fenómeno que Sergio Ramírez describe como el intento de llevar a la práctica "el montaje escenográfico de un sistema electoral que nos atara a la reproducción de un modelo político que permitiera a las clases sociales ya enterradas salir de sus sarcófagos a gobernar".

Nosotros postulamos que la propia acción de las masas y de su dirección revolucionaria, y el triunfo consiguiente, equivalen a una consulta popular; como consulta popular cotidiana significa el hecho de que el pueblo esté armado. Y más aún: esta ratificación cotidiana de la voluntad popular es más legítima que la que ofrece la democracia capitalista formal.

Tiene razón Jaime Wheelock cuando afirma:

Nosotros sabíamos perfectamente al triunfar la revolución que si el Frente Sandinista convocaba a elecciones iba a obtener un éxito rotundo. Sin embargo, el hecho de que el poder popular revolucionario haya surgido de una lucha armada masiva en la que participó, bajo diferentes formas de lucha, todo el pueblo nicaragüense, nos proporcionó una legitimidad de mayor calidad que la que podía darnos una elección civil. Incluso, desde el punto de vista jurídico reconocido por el mismo derecho burgués, las revoluciones son fuente de derecho y fuente de legitimidad porque son obra del pueblo.

Y agrega el comandante sandinista:

La revolución que surge de una lucha armada y la lucha armada misma es, en cierta manera, una consulta, porque implica una correlación de fuerzas tremendamente favorable a una causa. Podríamos decir entonces que en Nicaragua hubo "elecciones" antes del 19 de julio, pero bajo una modalidad militar; en contra, precisamente, de la legitimidad negativa, falsa, artificial, engañosa, que había usado el somocismo, puesto que el somocismo hacía elecciones. 
Se trata, pues, en contra de lo afirmado como cantilena por imperialistas y reaccionarios en general, y contra lo sostenido por ultraizquierdistas y radicalistas, de que éste no es ni un sistema totalitario o dictatorial ni una democracia formal de tipo burgués.

La revolución barrió con la vieja superestructura imperialista, creando un nuevo Estado, en el Estado popular nacional. Y con apoyo en el nuevo Estado, en el Estado popular nacional, el proceso transformó la vieja estructura economicosocial oligárquica. Con base en una economía mixta, con un sector estatal poderoso, iníció la creación, en su totalidad, de una nueva sociedad. O si se quiere se comenzó a transitar hacia una nueva sociedad, una sociedad socialista, sobre la base de un régimen democrático popular, que como ya señalamos, rebasa lo meramente superestructural e hinca su garra transformadora en la propia estructura económica y social.

El concepto de democracia popular no puede desligarse, si lo pensamos en relación a países atrasados y periféricos, de la urgente necesidad de realizar cambios estructurales profundos. Por otra parte, la democracia formal burguesa tiene límites insalvables en los países capitalistas periféricos, si de asegurar a las masas la cobertura de sus necesidades o derechos básicos se trata. Una comparación breve entre lo que ocurre hoy en Cuba y en Costa Rica, en cuanto a la satisfacción de las necesidades de las grandes mayorías, es elocuente al respecto, por más que el ruido de la lucha ideológica del imperialismo y sus aliados locales se empeñe en oscurecerlo y confundirlo todo.

Aspecto esencial en toda esta problemática es el hecho de que el concepto democracia no está desligado de la índole de la propiedad de los instrumentos y medios de la producción. Es innegable que allá donde tos medios e instrumentos fundamentales estratégicos de la producción están en manos de un Estado popular revolucionario y planificador se logra la posibilidad de lograr la cobertura satisfactoria de las necesidades básicas de las masas. Esto no sucede en aquellas democracias formales que hacen de la propiedad privada un mito intocable.

La primera expresión de la voluntad colectiva mayoritaria en Nicaragua fue la amplia participación de hombres, mujeres, ancianos y niños en la guerra popular revolucionaria. La participación fue general y heterogénea, de grupos provenientes de los más diversos estratos productivos y de marginados sociales. Esto otorgó al proceso un peso de clases no proletario, en el sentido clásico, sino popular. La clase obrera nicaragüense, dado el nivel de las fuerzas productivas, era cuantitativamente de poco peso. No se extraigan conclusiones precipitadas de lo anteriormente escrito en relación con la hegemonía clasista del proceso. La participación del pueblo - expresión diáfana de una voluntad soberanano sólo se dio en el terreno militar sino en las primeras formas de organización civil (Comités de Defensa Civil) bajo los cuales la población creó los gérmenes de lo que serian los Comités de Defensa Sandinista, encargados, después del triunfo, de la organización comunal por manzanas, la defensa, tareas de salud y educación, etcétera.

Después del triunfo armado, han madurado una serie de instancias de representación, participación, organización $e$ integración colectivas y populares. Dentro de ellas debe mencionarse el Consejo de Estado, integrado por representantes de organizaciones políticas, gremiales, sindicales, populares y de la empresa privada. El Consejo de Estado, expresión de pluralismo politico y de representatividad, fue constituido a principios de 1980. 
El pueblo se encuentra organizado y representado en multitud de entidades. Funciona así la Central Sandinista de Trabajadores (CST) y diversas centrales sindicales más, algunas de las cuales sostienen posiciones disidentes. En tales entidades se organizan y hacen representar los obreros. Funciona la Asociación de Trabajadores del Campo (ATC). Las mujeres se organizan y hacen representar en la Asociación de Mujeres Nicaragüenses Luisa Amanda Espinoza (AMNLAE). Los jóvenes en la Juventud Sandinista 19 de Julio. Las etnias en Misurata. Los niños en la Asociación de Niños Sandinistas. Los pequeños productores agrícolas y ganaderos se organizan y hacen representar en la Unión Nacional de Agricultores y Ganaderos (UNAG), etc. En las futuras elecciones de noviembre participarán varios partidos políticos, de las más disímiles ideologias, incluyendo aquellas contrarias al proyecto revolucionario.

El pluralismo político funciona en la nueva Nicaragua. Cuando Estados Unidos se empeña en hacer exigencias en tal sentido, lo que esconde es que su propósito real es el control del poder. La libertad de expresión del pensamiento y la libertad de prensa tienen vigencia, incluso con una amplia tolerancia para la propaganda contrarrevolucionaria. Igualmente, los derechos humanos, sin excepción, se hacen respetar, como regla general, por el Estado popular sandinista.

Aspecto importante es el fundamento económico del proyecto revolucionario: la economia mixta. El Área de Propiedad del Pueblo (APP), y la de propiedad privada burguesa funcionan. Hay empresas de inversión mixta, estatal y privada. El hecho de que las reglas del juego, en cuanto a la burguesía sobreviviente, las imponga el Estado popular, es consecuencia del martirologio y lucha de las propias masas trabajadoras que constituyeron el sujeto de la revolución.

También se revela la estructuración de la sociedad, de índole democrática, en el hecho simple que nos ofrece el pueblo armado y organizado en el Ejército Popular Sandinista (EPS), las Milicias Populares, los Batallones de Reserva, etcétera.

Mantenemos el criterio - dice el comandante Jaime Wheelock - de consultar a nuestro pueblo en la mayor parte de las decisiones. Y de hecho mantenemos una consulta permanente con los diversos sectores sociales, algunas veces informalmente y otras de manera formal. Aquí se ha venido desarrollando, desde lo más profundo de la sociedad, un conjunto de normas y de sistemas de participación que van constituyendo la prefiguración de una nueva democracia. Además de la práctica del Consejo de Estado, mantenemos constantes discusiones con el pueblo, a través, por ejemplo, de la comparecencia de la Junta de Gobierno en diferentes partes del país: en barrios, fábricas, en el campo, en fin, en todo el ámbito nacional. Los trabajadores participan en la conducción de las empresas; las localidades están gestionadas por las bases; las organizaciones populares participan en la formulación de las principales medidas gubernamentales a través de los consejos de política; por ejemplo, de reforma agraria, de producción industrial, agropecuaria, que están integrados prácticamente a todos los organismos de los cuales se pueden desprender decisiones importantes.

De lo anteriormente expuesto se deducen algunas conclusiones:

1. Es un concepto de democracia totalizador el que nos debe servir para 
analizar el significado de la democracia en América Latina y demás paises del Tercer Mundo: una democracia que rebasa lo superestructural y hunde su raíz en las transformaciones de las estructuras económicas y sociales y desde luego en el replanteamiento de nuevas relaciones con el imperialismo, sobre la base del respeto a la autodeterminación y la soberanía nacional.

2. Los procesos revolucionarios en Guatemala y El Salvador tienden hacia la implantación de democracias populares. ${ }^{16}$

3. Nicaragua es ejemplo de un régimen de transición hacia una nueva sociedad, de índole socialista, con fundamento en el funcionamiento de una democracia popular.

4. Costa Rica es un país de democracia formal capitalista. El régimen democrático costarricense se encuentra amenazado por riesgos enormes, como el surgimiento del militarismo. La democracia burguesa costarricense jamás ha cubierto las necesidades fundamentales económicas, sociales y culturales de toda la población. Se trata de una democracia no liberada de la dependencia imperial.

5. Honduras avanza en el tránsito de una neocolonia a una colonia. Su régimen, de apariencia formal democrática, no lo es en el contenido. Es un gobierno cuya característica esencial es la de ser un apéndice colonial del imperialismo norteamericano.

6. En El Salvador, los "poderes populares" creados por el proceso revolucionario son el germen de lo que podría ser el nuevo Estado popular. El régimen presidido por José Napoleón Duarte - y la Democracia Cristiana - no debe ser calificado de democracia porque tal régimen no puede funcionar en un país intervenido, convertido en protectorado o neocolonia, cuya vida total se decide en Washington (la Casa Blanca y el Pentágono) y cuya economía y fuerzas militares dependen absolutamente de Estados Unidos.

Las anteriores no son sino hipótesis generales. Este artículo tiene por finalidad principal defender la tesis de que el método de análisis de la democracia en cualquier país latinoamericano debe superar las generalidades (de las cuales por cierto no escapa el presente trabajo) y orientarse a aprehender la realidad concreta, a través de la investigación en torno a los diversos espacios (y celdillas) concretos que configuran la totalidad dialecta social. Elementos minimos, indispensables, de un método de investigación de la democracia aparecen esbozados al principio de este ensayo.

La ciencia política de los países tercermundistas, periféricos, hundidos en la degradación integral y progresiva, determinada por el capitalismo imperial del centro, no puede continuar dependiendo de científicos sociales del capitalismo desarrollado, norteamericano o eu ropeo. Es preciso y urgente superar, en todos los ámbitos, el colonialismo cultural. Una ciencia política legitimadora del orden capitalista y el sistema económico y político internacional presente, jamás servirá a los pueblos y naciones del Tercer Mundo, "los malditos de la tierra".

Indaguemos la verdad, que siempre es concreta, sobre cómo se perfilan las expresiones democráticas o antidemocráticas en los múltiples espacios concretos de la totalidad social, se trate de Nicaragua o Costa Rica, de Cuba, el Perú o Ecuador; de Israel o Angola...

I" Un análisis especifico sobre el régimen "civil" de Vinicio Cerezo está fuera del objeto de este trabajo. 